Universidad Nacional de La Plata

Facultad de Humanidades y Ciencias de la Educación

Departamento de Sociología

\title{
¿Más allá de "subcultura"? Apuntes sobre el fanatismo por la animación japonesa a partir de los planteos de Dick Hebdige
}

\author{
Beyond "subculture"? Notes on anime fandom considering Dick \\ Hebdige's arguments
}

\section{Federico Manuel Álvarez Gandolfi *}

* Universidad de Buenos Aires, Instituto de Investigaciones Gino Germani -CONICET, Argentina | falvarez@sociales.uba.ar

\section{PALABRAS CLAVE}

Subcultura

Fanatismo

Anime

Otaku

KEYWORDS

Subculture

Fandom

Anime

Otaku

\section{RESUMEN}

El presente texto se propone problematizar la aplicación del concepto de subcultura en el análisis de las dinámicas de construcción identitaria y producción simbólica que tienen lugar a partir del consumo fan de series animadas japonesas anime- por parte de jóvenes habitantes de Buenos Aires. Dicho objetivo responde a que se considera que el abordaje de los grupos o colectivos de fanáticos en general, y de los otakus en particular-fans de los objetos de la cultura de masas proveniente de Japón-, en términos de subculturas, tiende a prescribirles cierta orientación de "resistencia", influida por los estudios culturales británicos y la obra de Hebdige. A su vez, se entiende que en el campo académico de estudios sobre estos fans, aún en vías de constitución, suele predominar la utilización de dicha noción sin desarrollar una problematización teórico-conceptual al respecto. Las reflexiones que aquí se plantean, entonces, parten de una investigación propia sobre las identidades culturales que construyen y los sentidos que producen los otakus sobre sus prácticas de consumo, la cual asume una perspectiva comunicacional y socioantropológica, e implica la aplicación de técnicas de observación participante y entrevistas abiertas, tanto cara a cara como vía plataformas digitales, para reconstruir su propio punto de vista.

\section{ABSTRACT}

This paper aims to problematize the application of the concept of subculture in the analysis of identity construction and symbolic production dynamics taking place from youth fan consumption of anime, located in Buenos Aires. This objective responds to the consideration of the approach of groups or collectives of fans in general, and particularly otaku -fans of Japanese mass culture-, in terms of subcultures, as tending to prescribe them some idea of "resistance", influenced by British cultural studies and Hebdige's work. In turn, it is understood that, in the academic field of studies on these fans, still in process of being established, the use of such notion prevails without a development of a theoretical and conceptual problematization. Therefore, the thoughts developed here are based on an own research about cultural identities and senses produced by the otaku from their consumption practices, assuming a communication and socio-anthropological perspective, and involving participant observation and open interviews techniques, face to face as well as digital platforms mediated, to reconstruct their own point of view.

Fecha de recibido: 09/06/2017 | Fecha de aceptado: 24/08/2017 | Fecha de publicado: 28/12/2017 


\section{Consideraciones iniciales}

Hace ya casi dos décadas que el sociólogo Rogers Brubaker y el historiador Frederick Cooper (2001) advirtieron cierto uso y abuso del término identidad en las ciencias sociales, por lo que este suele tener un significado muy ambiguo: puede ser muy restringido o muy amplio. El significado restringido es asociado por estos autores con un sentido fuerte propio de los enfoques esencialistas, desde los cuales se subraya la igualdad entre personas que comparten ciertos atributos categóricos dentro de un grupo cerrado. Por su parte, al segundo tipo de significado lo vinculan con un sentido débil que sería propio de los enfoques constructivistas, los cuales ponen el foco en las autocomprensiones subjetivas desarrolladas de modo procesual, contingente y fragmentario. El problema es que el término identidad tiende a ser usado para indicar a la vez estos dos sentidos contradictorios entre sí. Es por ello que Brubaker y Cooper plantean ir "más allá de identidad", desplazando tanto la ambigüedad del concepto como sus connotaciones reificadoras.

Pese a que pueda estarse de acuerdo con que los reparos de estos autores resultan pertinentes, igual de significativos son los planteos de Stuart Hall (2011) con los que pretenden discutir. Podría pensarse que la importancia de la deconstrucción que hace Hall del concepto identidad, despojándolo de toda reificación, consiste en que la reivindicación de su uso en tanto categoría de análisis se sostiene en "su carácter central para la cuestión de la agencia" (2011, p. 14), pues permite reflexionar sobre cómo los sujetos pueden identificarse o no con ciertos discursos. Si se extrapolan estas advertencias de modo articulado, es posible llegar a la consideración de que es necesario explicitar el sentido con el cual se utilizan los términos para analizar problemáticas contemporáneas relacionadas con las dinámicas de construcción identitaria, en las cuales, por otro lado, el fanatismo cobra un rol central como "fondo de recursos" (Borda, 2012).

De modo análogo a dicha discusión, entonces, en este artículo se propone una posible recuperación de los planteos realizados desde los estudios culturales británicos para reflexionar sobre los sentidos en que en la época actual podría pensarse -o no- al fanatismo en general, y al grupo o colectivo de fans del anime en particular, en términos de subcultura. Para ello, se considerará fundamentalmente la obra de Dick Hebdige (2004), pues es la más referida por las investigaciones escasas, aisladas y dispersas, que conforman lo que podría entenderse como el estado del arte del campo académico de estudios sobre otakus (Balderrama Gastelú y Pérez Hernáiz, 2009; Perillán, 2009; Cobos, 2010; Ito et al., 2012; Del Vigo y Carpenzano, 2014; García Núñez y García Huerta, 2014).

Asimismo, se retomarán datos construidos a partir de un trabajo etnográfico propio que viene desarrollándose en Buenos Aires desde 2013 y continúa a la fecha. Este consiste en la articulación entre aproximaciones "territoriales", in situ, y "virtuales" a las instancias de socialización entre pares en las que se involucran los propios sujetos estudiados: eventos o convenciones, donde estos fans se encuentran presencialmente los fines de semana, y plataformas digitales -principalmente grupos de Facebook y canales de YouTube- en los cuales los otakus establecen interacciones cotidianas online ${ }^{1}$.

Lo que se sostiene aquí es que las investigaciones sobre el fanatismo por los objetos de la cultura de masas japonesa antes citadas tienden a no explicitar lo que entienden por subcultura, más allá de la supuesta asociación del término con cierta "alternatividad", aparentemente expresada en un estilo de vida "herético e irreverente" que caracterizaría a los grupos de fans en general, y a los otakus en 
particular. Por lo tanto, en los siguientes apartados se reflexionará sobre los sentidos en que estos jóvenes fans pueden o no ser conceptualizados como miembros de una subcultura.

\section{Los medios, el sentido común y su efecto ideológico: la subalternización de los otakus}

En un trabajo anterior (Borda y Álvarez Gandolfi, 2014) se señaló que, en Argentina, las distintas representaciones televisivas sobre los fans de los objetos de la cultura de masas japonesa tienden a ponerlos en escena a través de estereotipos y a estigmatizarlos como portadores de patologías en tanto "solitarios", "obsesionados", "excesivos", "recluidos", pertenecientes a un "entorno extraño", "peligrosos" que están inspirados por "cultos oscuros y satánicos", "vagos" que realizan actividades "inútiles" como "ver dibujitos" todo el día" y "no estudiar ni trabajar", "enfermos" que pueden perder el sentido de la realidad al sumergirse en mundos ficticios, o "ridículos" que gastan dinero en muñecos y "se disfrazan a pesar de ya no ser niños" coincidir con los modos en que los propios otakus suelen advertir que son percibidos por los miembros de su familia y sus compañeros de escuela o trabajo (Álvarez Gandolfi, 2014).

Por lo tanto, podría pensarse que los otakus serían desacreditados y despreciados por la ideología dominante, desprestigiados como un "otro peligroso" en tanto su "diferencia" implica un "desafío" a la representación totalizante de la colectividad. En este sentido, compartirían una de las características que Dick Hebdige (2004) adjudica a los miembros de las subculturas como insertados dentro de sociedades que se oponen a ellos. Extrapolando los planteos de este autor, los fans del anime conformarían una subcultura porque "son vistos como amenazas para el orden público o como inofensivos bufones" (Hebdige, 2004, p. 15).

Los jóvenes otakus serían concebidos como "amenazas" para el orden dominante naturalizado porque se comprometerían con personajes de ficción "perdiendo todo contacto con la vida real", y serían concebidos como "bufones", en tanto sujetos "ridículos", lo que a su vez también constituiría una categorización social indeseable, en la medida en que "juegan a disfrazarse" y el juego es una actividad desplazada generacionalmente: solamente los niños pueden disfrazarse sin sufrir una crítica social, y se supone que los jóvenes se encuentran en una etapa de transición hacia la adultez.

Por otro lado, estas apreciaciones peyorativas hacia ellos, tanto mediáticas como sociales, también podrían responder a los vínculos de los otakus con la generación juvenil, usualmente subordinada en relación con los adultos (Chaves, 2010; Reguillo Cruz, 2012; Saintout, 2013), negativizada, marginada simbólicamente, entendida como una etapa transitoria que es necesario superar,

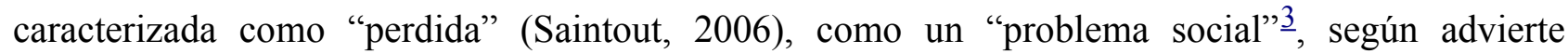
Hebdige. "Problema social" si retomamos los aportes de la sociología de la desviación (Becker, 2012), según los cuales los grupos asociados con el delito -“aunque en nuestro caso los 'delitos' se limiten a una mera infracción de códigos" (Hebdige, 2004, p. 14) 4 son etiquetados mediática y socialmente de modo negativo y hostil, construidos como "un otro desviado" de la norma por los grupos dominantes que definen los límites de los comportamientos aceptables. La ecuación en este caso sería: joven $o t a k u$ = vago, potencialmente peligroso o ridículo; de aquí su subordinación.

Los jóvenes fans de los objetos de la cultura de masas japonesa, entonces, podrían ser pensados como miembros de un grupo social subalterno, en un sentido gramsciano, respecto de la cultura 
hegemónica que sostiene un punto de vista centrado en el mundo adulto, por lo que ocuparían una posición subordinada dentro de la economía simbólica. Y en esta ubicación en una posición subordinada dentro de la economía simbólica, como se anticipó, los medios ocupan un lugar primordial, pues tratan de controlar y disciplinar el peligro potencial que ven en los grupos subculturales, demonizándolos y generando un pánico moral (Cohen, 1972b, citado en Hebdige, 2004, p. 136) frente a ellos, en tanto se los considera amenazantes de los intereses y valores "normales" de la sociedad. Al "obsesionarse con dibujitos animados" y "resistirse a crecer", no se convertirían en miembros productivos del orden social.

En efecto, según plantea Stuart Hall (1981), los medios de comunicación configuran y hacen circular sistemas de significados sociales a través de los cuales las personas se representan a sí mismas y a los demás, y dan inteligibilidad al mundo que las rodea. Dicha configuración implica la legitimación de algunos sentidos que son seleccionados y promovidos, y la deslegitimación de otros que son excluidos, lo que da cuenta de su "efecto ideológico" en tanto "clasifican el mundo dentro de los discursos de las ideologías dominantes" (Hall, 1981, p. 251). Así trazan los límites entre lo normal y lo desviado, vehiculizando las relaciones jerárquicas de poder entre los sujetos. En este caso, se trataría de las tensiones entre los valores tradicionales cercanos a "los adultos" y un modo de ser joven deslegitimado, en tanto que "improductivo", porque se lo asocia con cierta pretensión de evitar asumir responsabilidades como estudiar o trabajar.

Desde la matriz gramsciana en la que se inspira Hall, podría pensarse que los sistemas de significados sociales que los medios configuran y hacen circular contribuyen a la construcción de un sentido común que es funcional a los intereses de los grupos sociales hegemónicos que conforman el bloque histórico de poder mediante una alianza provisional (Gramsci, 1981, citado en Hall, 1981). Aquí hay que tener en cuenta que algunos grupos sociales "tienen menos poder para producir e imponer al mundo sus definiciones del mundo" (Hebdige, 2004, p. 30), definiciones que -producidas e impuestas por los grupos dominantes- establecen el eje central a partir del cual se define lo que resulta desviado.

Asimismo, como señala Víctor Lenarduzzi (2005), la revalorización gramsciana de la especificidad de las superestructuras hace necesaria una vinculación de la ideología con las formas concretas de la conciencia, para evitar entenderla como algo falso o bajo reduccionismos economicistas y clasistas. Por lo tanto, cabe advertir cómo en el sentido común suelen sedimentarse los marcos de referencia ideológicos dominantes, cuyos presupuestos aparecen como incuestionables, por lo que pueden ser reconocidos de modo instantáneo, y definen ciertos límites dentro de los cuales puede experimentarse el mundo. A su vez, es en relación con esos límites que se definen los desvíos.

\section{El desvío de la norma en el caso de los otakus: algunas preguntas en torno del consumo fan de objetos de la cultura de masas}

Ahora bien, ¿cuál sería la "mera infracción de códigos" -tomando prestadas las palabras de Hebdige- que implicaría la "subcultura" otaku? ¿En qué sentidos el fanatismo por el anime implicaría un "desafío" a los "discursos de las ideologías dominantes”? ¿Por qué constituirían, desde el punto de vista de los medios y el sentido común, un grupo "desviado de la norma" y sus prácticas resultarían inaceptables? ¿Por qué los sentidos que estos jóvenes adjudican a su consumo 
de anime son deslegitimados y excluidos? ¿Por qué generan un pánico moral? ¿En qué sentidos amenazarían los intereses y valores "normales" de la sociedad?

En principio, podría pensarse que los fans del anime desviarían la norma tanto por su consumo de objetos de la cultura de masas japonesa, que resultarían "raros" desde una mirada occidental, como por su asociación con valores generacionales opuestos a los principios tradicionales de los adultos. La aparición de su "diferencia" en la escena pública resultaría "exótica" y, en consecuencia, debe ser clasificada para poder contener el desafío al orden social que representaría. En este sentido, las calificaciones peyorativas que circulan en los discursos hegemónicos sobre ellos podrían responder a que los otakus, las prácticas que desarrollan y los productos mediáticos que consumen son considerados ilegítimos.

Si bien hoy la ampliación semántica del término fan en el idioma español ha hecho ganar terreno a sus sentidos neutrales ingleses de mera "afición, afinidad o entusiasmo" (Borda, 2012), los jóvenes otakus continúan siendo ubicados en una posición de subalternidad cultural. De este modo, serían subordinados respecto de otros universos simbólicos considerados más legítimos, asociados en general con el mundo adulto que organiza su vida en torno del empleo y la cultura letrada hegemónica. Esto se manifiesta en la importancia que se asigna al trabajo y a la escuela en la conservación de los valores tradicionales, los cuales parecieran ser amenazados por la formación de las identidades juveniles sobre la base de las industrias culturales: como se anticipó, "no trabajan ni estudian" suele ser una de las acusaciones esgrimidas contra los jóvenes fans del anime y, de allí, su "anormalidad", que en su caso se potenciaría por el hecho de que "siguen viendo dibujitos animados" -animaciones que a su vez resultan exóticas por su condición japonesa- cuando se supone que "tienen que crecer".

Los modos mediáticos y sociales de dar inteligibilidad a la "diferencia" - a su "siniestra presencia" como la denomina Hebdige (2004, p. 15)-, que en este caso sería cristalizada por los otakus, clausuran la comprensión de la lógica de sus prácticas, su racionalidad, su positividad, su potencialidad para la construcción de identidades y configuración de comunidades (sub)culturales de pertenencia, su modo particular de consumo de productos mediáticos a partir del cual realizan nuevas producciones textuales como fanfics, fan art o AMV $\underline{5}$.

Asimismo, dado el "exotismo" de sus componentes visuales, su diversidad y su complejidad tienden a ser reducidas a la práctica del cosplay, por lo que hay que "sospechar de las categorías del sentido común que se ciernen sobre la subcultura” (Hebdige, 2004, p. 186). Al igual que las subculturas juveniles que surgen de la música popular - rock, jazz, reggae, punk- en el contexto de las relaciones de rechazo o asimilación entre la clase obrera blanca y la inmigración negra en la Gran Bretaña de posguerra -teddy boys, mods, hipsters, punks, skinheads, rastafaris-, "[c]asi siempre, lo que primero atrae la atención de los medios son las innovaciones estilísticas de la subcultura" (Hebdige, 2004, p. 129), cuyas representaciones permiten reconocerlas y procesarlas como presencias siniestras en el mundo social.

En otras palabras, las representaciones mediáticas y sociales hegemónicas sobre los otakus parecieran no reconocer legitimidad alguna a los sentidos que tienen sus prácticas. Por lo tanto, podríamos preguntarnos cómo estos jóvenes fans construyen identidades a partir de las prácticas 
socioculturales que desarrollan en torno del consumo de los productos mediáticos japoneses, $\mathrm{y}$ cuáles son los vínculos que se entablan entre la cultura dominante asociada con el mundo adulto, la cultura de masas estadounidense y argentina, dominantes en el contexto nacional, y el universo simbólico que elaboran alrededor del anime en función de sus diferentes contextos locales de apropiación.

Pero, para tratar de responder a las preguntas hasta aquí planteadas, habría que explicitar algunos puntos de partida como el de distanciarse de algunas posturas pesimistas, sostenidas a partir de la teoría crítica elaborada por los intelectuales de la Escuela de Frankfurt, que no permitirían ver en los productos de las industrias culturales más que un vehículo de la alienación y la dominación ideológica. Cabe aclarar que esta visión es incluso propuesta también en algunas obras producidas en el marco de los estudios culturales británicos de la Escuela de Birmingham, donde se percibe que la cultura de masas y su producción en serie son enemigas tanto de las tradiciones de la "comunidad obrera", que deberían ser defendidas, como de las de la "alta cultura", a las cuales fragmentaría y degradaría.

Más que fragmentación y degradación de un universo simbólico supuestamente autónomo y puro, podría pensarse que entre la cultura cotidiana de las personas y la cultura de masas hay vínculos circulares: la segunda surge de la primera, y no solamente retomando y moldeando sus sensibilidades, sino también dando lugar a la producción de nuevos sentidos e interpretaciones. Además, en el caso de los fans, puede dar lugar a la configuración de nuevos universos simbólicos compartidos, que implican prácticas específicas de significación identitaria y comunitaria a partir de las identificaciones comunes que se generan con los productos mediáticos.

En este sentido, resulta productiva la propuesta de Douglas Kellner (2011), consistente en lograr una articulación compleja entre las potencialidades y limitaciones de la teoría crítica de la Escuela de Frankfurt y los estudios culturales británicos de la Escuela de Birmingham. Para ello, hay que tener en cuenta que la cultura mediática proporciona materiales en torno de los cuales construir identidades de clase, raza, generación, nacionalidad, sexo y género. Y, en este sentido, puede pensarse al fanatismo como fondo de recursos disponible para forjar mecanismos de interpelación y reconocimiento, para involucrarse en procesos colectivos e individuales de constitución identitaria (Borda, 2012), o para formar fandoms, es decir, configurar grupos de fans o culturas fan.

De aquí que también sea necesario explicitar lo que se entiende por cultura. Y en este punto resulta oportuno coincidir con Raymond Williams (1981, pp. 13-14), para quien es necesario lograr una convergencia práctica entre dos sentidos del término: su sentido socioantropológico, a partir del cual se entiende a la cultura como todo un modo de vida diferenciado, dentro del cual un sistema significante específico y compartido se considera como constitutivo de todas las formas de actividad social; y su sentido más especializado y corriente, a partir del cual se la entiende como conjunto de actividades intelectuales y artísticas, pero que no solamente incluye las artes y formas tradicionales de producción intelectual, sino también todas las prácticas cotidianas.

A partir de esta propuesta, resultante de los debates en el interior de la Escuela de Birmingham, surgió una de las primeras compilaciones de trabajos sobre las subculturas (Hall y Jefferson, 2010), provenientes también de dicha escuela y en los cuales Hebdige se basó y participó. Estos trabajos 
refieren a la capacidad que tienen los grupos juveniles de clase obrera británica heredera de la posguerra de desafiar los condicionamientos ideológicos dominantes, generando representaciones y prácticas rituales contrarias a las de la cultura hegemónica y entablando con ella relaciones de "resistencia" mediante la adopción de un estilo particular e irreverente, donde se expresan sus valores.

Aquí cabe advertir la influencia gramsciana que atraviesa estos planteos, en tanto se entendería a la cultura como un campo de lucha por la hegemonía pues, como se anticipó, en el sistema significante específico y compartido, constitutivo de todas las formas de actividad social -según las ideas ya señaladas de Williams-, hay sentidos que se erigen como hegemónicos y otros que quedan relegados a la subalternidad. Los significados identitarios que tienen para los otakus sus prácticas de consumo constituirían un ejemplo de sentidos subalternos, es decir, "subculturales": más allá de su situación general de subordinación simbólica, "la identidad otaku" tiende en efecto a ser reivindicada como "alternativa" por estos fans, quienes llegan a afirmar: "Mejor ser otakus con orgullo que ser normales o un calco de lo que quiere la sociedad: ser normal apesta". Pero ello no quita que, dentro de su propio grupo, existan disputas a partir de las cuales se definen cuáles son los sujetos, sentidos, prácticas e identidades que cobran más valor o legitimidad, particularmente en función de la pertenencia generacional y de clase de sus miembros (Álvarez Gandolfi, 2016).

En definitiva, y retomando la discusión teórico-conceptual alrededor del término identidad con la que se inicia este artículo, se trata de recordar que la noción cultura -tan polisémica y confusa como el primer término- resulta más productiva analíticamente cuando no se la utiliza en un sentido esencialista o reificado. Si bien pareciera que esta advertencia resulta repetitiva porque tal sentido ya habría caído en descrédito (Grimson, 2010), todavía pareciera que "fuera del mundo académico, no ceden las visiones de la cultura que la identifican con las bellas artes, ni los esencialismos [fundamentalistas]" (Grimson y Semán, 2005, p. 2).

Por lo tanto, hay que insistir en que "las culturas" -así como también "las subculturas" que se diferencian tanto de ellas como entre sí- exigen una conceptualización en tanto que universos simbólicos diferenciales, tramados por articulaciones complejas y sociohistóricas de elementos, representaciones, prácticas y significados, sedimentados pero variables, heterogéneos, como propone Alejandro Grimson (2010).

$\mathrm{Y}$, en este último sentido, este autor entiende que tampoco puede postularse la existencia de conjuntos unificados, coherentes y armónicos, con fronteras fijas y claramente delimitables, olvidando que la interacción, las alianzas, los préstamos, las negociaciones, la oposición, la transformación, la contradicción, el conflicto y las desigualdades son dimensiones constitutivas de las culturas, así como de las identidades que, por otro lado, no mantienen con las culturas una relación de implicación simple.

Uno de los mayores riesgos que conlleva tal olvido consiste en que, mediante la homogeneización, las diferencias conceptualizadas -en el caso específicamente aquí problematizado, las que marcarían la existencia de los otakus - aparecen como irreductibles o esenciales: se confunden las categorías identitarias que expresan sentimientos de pertenencia a un grupo o colectivo como uniformidad cultural, y no se contempla la posible variabilidad de sus significados para sus 
miembros. Si bien otaku se ha convertido en una categoría de práctica universalmente aplicada para referir a los fans del anime, cobra diferentes sentidos -negativos, neutrales o positivos- según el contexto de aplicación.

En lo que respecta a la mayoría de los abordajes académicos sobre los fans del anime ya referidos, su conceptualización como subcultura otaku, al centrarse en la condena de su situación de subalternidad y estigmatización, suele implicar su celebración como sujetos "alternativos" y "solidarios", y por ello "resistentes", en relación con otros fandoms y tendencias comerciales dominantes en Occidente. Resistencia que a su vez se expresaría en su "estilo herético e irreverente".

En este sentido, podría trazarse una analogía con lo que ocurrió con la primera etapa de los estudios sobre fans [fan studies] en general a principios de los noventa en la academia anglosajona: como señala Borda (2012), frente al panorama sociomediático y académico de patologización de los fanáticos -representados como "obsesivos" y "antisociales"-, Henry Jenkins, uno de los mayores exponentes de este campo, se propuso conceptualizarlos de modo idealista como una comunidad subcultural compleja y diversa, crítica y productiva, alternativa -“más humana, amistosa, fraternal"- en relación con los valores dominantes -competencia, individualismo- que atraviesan los ámbitos familiares, escolares y laborales.

Podría pensarse que esta primera etapa analítica es necesaria para tomar distancia de las miradas negativizadoras sobre este fenómeno sociocultural y acercarse a sus lógicas propias, focalizando sobre sus dimensiones compartidas y reponiendo su positividad. Pero tiene que ser complementada con otra instancia de identificación y descripción de las jerarquías internas para no autonomizar al fandom otaku, reduciéndolo a una inversión de sentidos hegemónicos o a una reivindicación etnocéntrica de valores de resistencia defendidos por el analista. Estas operaciones impiden ver no solo los efectivos mecanismos internos de exclusión que operan allí, sino también otros significados producidos por los propios actores implicados que puedan ir más allá de pares dicotómicos como normalidad/anormalidad, madurez/inmadurez o dominación/alternatividad.

\section{Relecturas contemporáneas de Dick Hebdige: ¿puede hablarse de un "estilo subcultural" otaku?}

Tras el racconto de reflexiones teóricas presentado, podemos volver ahora al caso particular de los otakus, para cuyo análisis será necesario hacer ciertos reparos en relación con los planteos de Hebdige. ¿Constituyen los otakus un "estilo con implicaciones subversivas" al igual que, por ejemplo, los punks?

\section{Bricolaje y homología}

Por lo pronto, los otakus sí podrían ser considerados como miembros de un grupo subordinado, al menos en función de las representaciones mediáticas y sociales, estigmatizantes y hegemónicas, a las que se hizo referencia en el inicio de este trabajo. Su "diferencia" implica una infracción de códigos y sus prácticas implican una violación simbólica del orden social naturalizado, un "desafío" al mundo normativo, pues se trata de jóvenes que se suponen en camino hacia la adultez y parecieran querer retrotraerse a actitudes infantiles y extenderlas de modo indefinido: miran 
"dibujos animados", coleccionan "muñecos", se "disfrazan" como "niños", no estructuran sus identidades a partir de referentes tradicionales como la escuela y el trabajo, pues se sienten más representados por el anime, cuyo auge en América Latina se remonta a la década del noventa.

Pero lo que no es del todo seguro en el caso de los otakus es que sus tensiones con los grupos dominantes puedan leerse textualmente en la superficie del estilo que adoptan, por lo que este no podría ser entendido como "expresivo", como sí lo es el estilo punk según Hebdige. En efecto, los signos de su identidad "desviada" son objetos "triviales" a los cuales estos jóvenes fans les atribuyen significados de pertenencia comunitaria "subcultural", a la vez que se convierten en su estigma: vestimentas de color oscuro, accesorios como pines o prendedores metálicos, gorros de animales, tinturas o pelucas de colores -azul, verde, blanco, amarillo, rosa, turquesa- y peinados particulares hacia arriba o con flequillo. Mediante estos elementos señalan una identidad que surge de la pertenencia a su comunidad de pares, comunicando referencias que solamente pueden ser captadas por los consumidores fans de las series animadas japonesas, en tanto dichos elementos provienen de ellas.

Por lo tanto, a diferencia de los punks, los otakus no mezclan detalles de épocas distintas ni reivindican el analfabetismo, ni tampoco parecieran comprometerse con una forma de rechazo del orden natural que genera "repulsión", en el sentido de los vómitos, escupitajos y esvásticas con las que Hebdige (2004, pp. 80-81) asocia al punk, cuyo sentido dentro de su estilo es el propio "sin sentido", la garantía del "caos" y del "escándalo".

En este sentido, el estilo otaku no presentaría un heterogéneo conjunto de significantes, que en todo momento pueden ser reemplazados por otros, como sí lo hace el punk. Por el contrario, en el caso de los fans del anime no pareciera haber una apropiación del vestuario de la cultura parental de clase de la cual surge, aunque sí, al menos en parte, de su sistema de valores y representaciones, el cual mantienen, como se verá más adelante. Los otakus no subvierten el vestuario propio de su cultura parental apropiándose de ella y otorgándoles un significado distinto, sino que directamente asumen pautas de vestimenta presentes en las series animadas japonesas que consumen.

En los términos de Claude Lévi-Strauss, retomados por Hebdige, entonces, el estilo otaku no implicaría una práctica de bricolaje, en el sentido de combinar distintas mercancías o significantes de la cultura parental recuperándolos simbólicamente para su vida cotidiana y dotándolos de significados diferentes que entran en tensión con sus sentidos y usos convencionales. Ni tampoco podría hacerse referencia a una homología, en el sentido del orden interno coherente que dichos significantes articularían con los intereses de los miembros de la (sub)cultura a pesar de su diversidad, aunque sí en el sentido de que los elementos que adoptan los fans del anime expresan sus valores colectivos "alternativos", a partir de los cuales dan sentido al mundo y asumen una identidad grupal. Y, de nuevo, esa diferencia es la que suele condenarse como amenazadora o exotizarse como ridícula, algo que los propios otakus reconocen al referirse a los modos en que tienden a ser mirados como "loquitos" o "raros" (Álvarez Gandolfi, 2015).

En relación con esta última observación, podría pensarse que, mediante su estilo, los jóvenes otakus sí comunican intencionalmente una diferencia significante, una identidad grupal, y resignifican de modo positivo sus vínculos con "lo infantil" y "lo raro" -valorados negativamente por los discursos 
de las ideologías dominantes- afirmando que no quieren "ser normales" y que "siempre" van a escuchar a su "niño interno". Aquí cabe preguntarnos si, al invertir el sentido negativo de los discursos estigmatizantes que les son impuestos y que los marcan como "otredad" potencialmente "peligrosa" o "inmadura", sus prácticas estilísticas no terminan por ser alienantes, pues reafirman para distinguirse- la norma según la cual son señalados como subordinados. Parafraseando los planteos de Pierre Bourdieu sobre la paradoja de los dominados, esta es una "contradicción [insalvable] que está inscripta en la lógica misma de la dominación simbólica” (1988, p. 156). Incluso dicha resignificación también podría demostrar el poder de la ideología dominante, pues las culturas subordinadas se experimentan a sí mismas en términos prescriptos por sus marcos referenciales.

\section{El problema de la integración y la restricción al ocio}

Por otro lado, y en su mayoría, la "subcultura" otaku no deriva ni se diferencia de las formas y prácticas de una cultura parental de clase obrera más amplia: se trataría de jóvenes que se autoperciben como pertenecientes a los sectores medios, por lo que serían subordinados en el nivel de la cultura dominante, que tiende a condenar su modo de ser joven, porque no coincide con los valores adultos legitimados, pero no serían subordinados en el nivel de su cultura parental. Este sería uno de los límites que presentan los planteos de Hebdige para ser extrapolados al caso de estos fans y poder categorizarlos como "subcultura", pues este autor pareciera restringir dicha categoría a aquellos estilos "espectaculares" y "marginales" que tienen vínculos con la clase obrera. Es cierto, sin embargo, que el autor advierte que pone el acento sobre los jóvenes subordinados en función de su raza y clase -jóvenes "negros" y "obreros"- pues entiende que dichos clivajes han sido subestimados desde la academia. Tampoco puede perderse de vista que, en los últimos años, el fanatismo por el anime se ha extendido entre los sectores populares (Álvarez Gandolfi, 2016).

Por lo tanto, el estilo otaku no visibilizaría un desafío a los patrones culturales de los sectores medios en general -a excepción de en el modo particular que implica de ser joven-, pero sí expresaría una comunidad distintiva en relación con los patrones de los jóvenes, a quienes perciben como parte de los sectores medios "ordinarios", con quienes compartirían la misma posición de clase. Así, por ejemplo, se distinguen de quienes consumen productos estadounidenses provenientes de la industria Disney, o productos argentinos de Cris Morena, más allá de que estos consumos también se asocien con las clases populares.

Para hacer referencia a los sectores medios, Hebdige recurre a la definición de contracultura que se encuentra en la compilación de Stuart Hall y Tony Jefferson antes citada, distinguiéndola de la subcultura de clase obrera "por los perfiles explícitamente políticos e ideológicos de su oposición a la cultura dominante [...], por su creación de instituciones 'alternativas' [...] y su difuminación de las distinciones, tan rigurosamente mantenidas en la subcultura, entre el trabajo, el hogar, la familia, la escuela y el ocio" (2004, pp. 200-201). No obstante, los otakus no constituirían una contracultura en la medida en que no están comprometidos con una acción "política" -en el sentido tradicional y restringido del término-, no tienen "manifiestos", no están relacionados con ningún tipo de institucionalización. Por el contrario, y al igual que ocurre con las subculturas, su "oposición" solamente puede ser leída en términos simbólicos. 
El problema radica en que Hebdige (2004, pp. 177-178) se muestra preocupado por cómo el poder subversivo de las subculturas puede ser desactivado, en tanto ellas pueden ser reabsorbidas, incorporadas e integradas a la cultura dominante a través de las industrias culturales, pues para él las subculturas se constituyen en tensión con sus culturas parentales de clase tradicionales y, además, con la masificación. Se muestra preocupado por cómo los signos subculturales pueden ser reincorporados al sistema dominante de valores y sentidos a través de la cultura comercial o de masas, de modo que su desafío simbólico sería trivializado y reducido a mero espectáculo estilístico apto para el consumo público. Así, su otredad sería minimizada y convertida en mercancía que se produce en una escala masiva, transformándola en convencional, normalizándola. Según este autor, las subculturas rechazan las banalidades de la vida ordinaria y de la masificación, por lo que se relacionarían con el underground.

Sostener esto último si se pretende clasificar como subcultura a los fans del anime también es problemático. Los otakus sí rechazarían las "banalidades" de la vida ordinaria, razón por la cual la mayoría afirma que consume anime, dado que en él encuentran "valores más profundos", tanto en relación con los ámbitos familiares, escolares y laborales de socialización -donde se desenvuelven y claman no encontrar "contención"- como en relación con los productos mediáticos estadounidenses y argentinos.

Pero no rechazarían las "banalidades" de la masificación. O, al menos, no las de la cultura de masas japonesa, aunque sí las de la masificación dominante propia de las industrias culturales estadounidenses y, dentro del contexto nacional, argentinas. En relación con dichos productos orientales, los otakus dicen encontrar tramas argumentales profundas y complejas sobre diferentes aspectos de la vida diaria, drama, muerte, violencia, sexualidad $\underline{6}$, contradicciones existenciales, la valoración de la amistad por encima de la competencia, la importancia del esfuerzo y del sacrificio para alcanzar objetivos, romance, respeto por la naturaleza, distintos modos de concebir la religión. Comparándolos con los productos mediáticos estadounidenses y argentinos dirigidos al entretenimiento juvenil, en líneas generales estos fans afirman que "el anime es menos infantil, inocente y previsible", se identifican con sus "personajes imperfectos" y de "personalidad rara".

Entonces, ¿cómo sería posible sostener que jóvenes de clase media abocados al consumo de una cultura comercial constituyen una subcultura? ¿En qué sentidos? ¿Qué relaciones entablan con sus pares de clases populares, quienes están participando cada vez más en el fandom otaku?

En principio, podría afirmarse que los jóvenes otakus sí crean "alternativas", al vincularse con representaciones, prácticas, valores, expresiones idiomáticas que permean sus interacciones, y con productos mediáticos japoneses no dominantes en el contexto en el que viven. Es precisamente en estos vínculos donde podría radicar su "desafío simbólico", en tanto operan por fuera del mainstream estadounidense y argentino, tanto de sus productos como de sus mercados y redes de distribución, a los cuales tienden a rechazar: estos fans suelen acceder a las series animadas japonesas a través de sitios web creados y mantenidos por ellos, pues son muy poco transmitidas por televisión abierta y por cable. Así, podríamos pensar que, al elegir consumir productos de las industrias culturales japonesas - lo que les es posible gracias a la existencia de un panorama socioeconómico contemporáneo globalizado y mundializado-, estos fans rechazan las tendencias homogeneizadoras de su contexto sociocultural occidental, dominado por series estadounidenses y 
argentinas.

En este caso, el fracaso del consenso, el desafío a la hegemonía que implica la emergencia de una subcultura, la cual como describe Hebdige "pone en jaque" el principio de unidad y cohesión social, se daría por el descrédito hacia la familia, la escuela, el trabajo, el Estado-nación, la Iglesia, los medios comerciales dominantes. Se relacionaría con un período histórico contemporáneo posmoderno, tal como lo define Terry Eagleton (1998), en el que se desconfía de los grandes relatos tradicionales que dan sentido al mundo y se pasaría a configurar un mundo de lo contingente, desunido y efímero, de identidades supuestamente incoherentes, dada la consolidación de un capitalismo descentralizado y el consumismo que ocasionan una pérdida de sentidos estables para orientar las prácticas en la vida colectiva.

En este sentido, habría que preguntarse también cómo procesan los jóvenes otakus este nuevo panorama caótico. Y, en el caso de los fanatismos, el consumo mediático aparece como el nuevo referente privilegiado a partir del cual poder experimentarlo, autoafirmarse y diferenciarse, encontrando sentidos propios. En este punto podríamos pensar que, como en la actualidad toda práctica está subsumida en relaciones mercantiles y el consumo se ha convertido en un aspecto naturalizado de la vida cotidiana, pareciera que ser fan de un producto mediático es algo convencional, normativo, en especial si se sigue la hipótesis de Libertad Borda (2012), que plantea que en las sociedades contemporáneas asistimos a una fanificación de las audiencias. No obstante, dentro de ciertos contextos particulares como el descripto, hay ciertos objetos de la cultura de masas cuyo consumo da lugar a prácticas de construcción identitaria y configuración comunitaria que no son normativas.

El anime y los otakus, como se trató de constatar hasta aquí, serían un ejemplo de esto último, pues dichos fans parecieran oponerse a las instituciones tradicionales en torno de las cuales el mundo adulto organiza su vida. Así, constituyen sus identidades individuales y colectivas a partir de la cultura de masas japonesa, en las cuales se sienten más representados y sobre cuya base configuran una comunidad (sub)cultural dentro de la cual se sienten más contenidos. Tal vez este desapego a dichas instituciones puede dar cuenta de la subordinación y deslegitimación simbólicas a las que son sometidos por parte de los medios y las personas "ordinarias", en tanto la cultura de masas en general suele ser considerada desde la perspectiva de la cultura dominante como una degradación de "lo culto" y, en el caso particular de la cultura de masas japonesa, como algo "bizarro" e "infantil".

A su vez, si partimos de la suposición de que nos encontramos transitando una etapa posmoderna, no se pretende celebrar o condenar una supuesta liquidez de los vínculos contemporáneos, una fragmentación social y un creciente individualismo, como se lo hace desde algunas posturas. Por el contrario - extrapolando los señalamientos de Hebdige-, la relación con la subcultura puede ser efímera-fluida-distractora, pero también puede ser permanente-persistente-fundamental, como lo es en el caso de los otakus argentinos, quienes buscan experimentar y sostener un sentido identitario y comunitario de "alternatividad". Es por dicha búsqueda que podría interpretarse que consumen anime, pues encuentran allí una fuente de significados alternativos dentro de su contexto nacional particular.

Por otro lado, Hebdige propone reflexionar teóricamente sobre los estilos espectaculares como 
textos, a la vez que restringe a las subculturas a prácticas rituales de resistencia limitadas al tiempo de ocio y a espacios en los que los jóvenes pueden encontrar cierta "autonomía" en relación con las instituciones adultas, lo que tiene como resultado el hecho de que pareciera no ser necesario un contraste empírico con los modos en que el estilo subcultural es experimentado por los propios sujetos $^{7}$. Si bien dichas prácticas rituales están presentes en el caso de los otakus -como por ejemplo la organización y asistencia a convenciones o eventos mensuales donde se congregan, en tanto les permiten sostener su identidad colectiva y sentirse parte de un grupo-, estos jóvenes también llevan su fanatismo a otros ámbitos de su vida cotidiana, más allá de los espacios de ocio o sus encuentros rituales $\underline{\underline{8}}$, y además mantienen relaciones diarias entre sí a través de plataformas digitales.

Esta observación requeriría de otra toma de distancia en relación con los planteos del autor para pensar a los otakus como "subcultura" pues, según ya se señaló, él subraya que dentro de la subcultura se mantienen de modo riguroso las distinciones entre el trabajo, la familia, la escuela y el ocio, en tanto esta "[o]pera exclusivamente en la esfera del ocio" (Hebdige, 2004, p. 131) y es "secreta" en los otros espacios. Por su parte, los fans del anime tienden a sostener su estilo en las esferas familiares, escolares y laborales, a diferencia de, por ejemplo, lo que puede inferirse de un testimonio recogido por Hebdige de un artículo periodístico: "No me vestiría de punk para ir a trabajar, hay un momento y un lugar para todo" (2004, p. 131).

\section{El problema de la clase}

Por último, es preciso retomar uno de los inconvenientes ya señalados para conceptualizar a los otakus como "subcultura": su pertenencia -en principio, mayoritaria- a los sectores medios, aunque cada vez más popularizada. Hebdige -basándose en las ideas de Phil Cohen (1972a, en Hebdige, 2004) - propone pensar a la subcultura como una "expresión espontánea" que implica la "resolución mágica" en el estilo de contradicciones estructurales compartidas, que en su caso son generadas por cambios demográficos, desaceleración económica y aumento del desempleo. A partir de esas contradicciones se emprenderían procesos de desafiliación generacional mediante prácticas estilísticas y prácticas simbólicas específicas, para distender el conflicto dentro de la nucleada

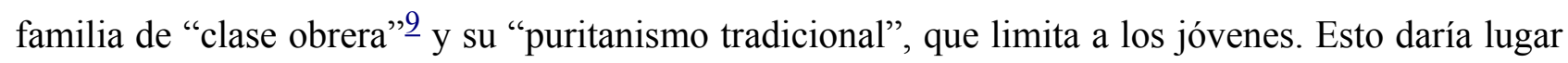
a un desplazamiento por fuera de ella y a la configuración de las subculturas.

¿Pero qué ocurre cuando en una subcultura convergen sectores juveniles de distintas clases? En efecto, y volviendo a extrapolar las observaciones del propio Hebdige, tratar de responder esta pregunta implica tomar distancia de algunas miradas según las cuales la posmodernidad conllevaría necesariamente la priorización de los intereses individuales por sobre los vínculos colectivos; la libertad para elegir entre infinitas opciones y una multiplicidad posible de identificaciones que se abrirían tras la pérdida de los sentidos estables tradicionales.

Por el contrario, hay que presar atención a las desigualdades que continúan operando en el interior de los propios sistemas de valores subordinados. En efecto, "la juventud" no es una comunidad de indiferenciados consumidores, dentro de la cual parecería que las distintas subculturas dependen menos de las pertenencias de clase de sus miembros, en tanto organismos independientes cuyo funcionamiento sería aparentemente ajeno a los contextos socioeconómicos más amplios. En este 
sentido, las subculturas no necesariamente son siempre "resistentes", sino que también pueden ser "conservadoras", o como sostiene Hebdige: "en ocasiones las culturas de resistencia en realidad sirven para reforzar, y no para debilitar, las estructuras sociales existentes" (2004, p. 221).

Para advertir y problematizar tal refuerzo se vuelve precisa la articulación entre un enfoque intergrupal e intragrupal. Así, si se entiende la resistencia como una noción que "describe la posibilidad de que sectores en posición subalterna desarrollen acciones que puedan ser interpretadas, por el analista o por los actores involucrados, como destinadas a señalar la relación de dominación o a modificarla" (Alabarces et al., p. 33), desde una mirada centrada en vínculos entre grupos, los otakus serían "resistentes" porque su presencia -mediante la visibilización de su estiloreivindicaría su "alternatividad". Pero, a la vez, entender a este fandom como parte de un orden sociocultural más amplio permite advertir el funcionamiento de mecanismos internos de distinción y de significados que nada tendrían de resistentes. Extrapolando las ideas de José Garriga Zucal, cabría preguntarse "si los sentidos descifrados en los gustos y consumos analizados, entendidos como expresiones de 'desafío' y de 'rechazo' al orden establecido, no expresa[n] más la postura del investigador que la de los sujetos investigados" (s/f, p. 195).

Es justamente por ello que resulta importante relacionar el concepto de clase con la autopercepción de los propios sujetos implicados por él, la necesidad de entenderlo como una categoría heurística bajo la cual subyacen experiencias subjetivas (Thompson, 1980). Experiencias subjetivas que se relacionan con juicios de valor social que las personas proyectan sobre sí mismas y los demás; evaluaciones y apreciaciones que no necesariamente coinciden con una "realidad objetiva", y que “afirma[n] una sola cosa sobre los miembros de una 'clase': que están en un nivel superior, en un nivel medio o en un nivel inferior" (Furbank, 2005, p. 122).

En el caso de los jóvenes fans del anime, como se anticipó, ellos parecieran mantener el sistema de valores y representaciones de su cultura parental de clase media, configurando su comunidad en función de los conflictos propios de una organización social clasista. Por lo tanto, dentro de su (sub)cultura se reproducen las relaciones de dominación y jerarquías sociales más amplias a partir del despliegue de mecanismos de segregación basados en lo que podría considerarse un "racismo de clase".

Esto se debe a que aquellos otakus que se autoperciben como parte de una "clase media" advierten una creciente presencia en su comunidad de sujetos a quienes, a su vez, perciben como parte de una "clase baja". Afirman que, tanto en las convenciones donde se reúnen y en los ciberespacios donde interactúan, como en las calles, hay cada vez más jóvenes que comparten sus consumos y exhiben su estilo. Pero valorizan este hecho como algo negativo, en tanto los califican como "pobres", "negros", "violentos", con "mal olor", que "tienen faltas de ortografía" y "escuchan cumbia villera", y en apariencia el anime no tendría "nada que ver" con ese tipo de música.

\section{A modo de cierre}

Las prácticas de significación que despliegan los fans del anime para constituir identidades individuales y colectivas en torno de su consumo podrían dar cuenta de la importancia de seguir reflexionando sobre estas problemáticas contemporáneas, tal como la explicita Hall (2011). En el 
caso que se analizó aquí se trataría de advertir la falta de reconocimiento de los otakus en relación con las instituciones tradicionales y su identificación con productos mediáticos que, dentro del contexto nacional particular, resultan extraños y deslegitimados.

En este último sentido, podría pensarse que las series animadas japonesas no constituyen textos mediáticos homogeneizados en el que se desdibujen las diferencias socioculturales, o al menos no lo hacen cuando son consumidas dentro de un contexto sociocultural distinto de aquel en el que son producidas masivamente. Por su parte, sus fans no sienten la necesidad de leer sus textos de modo "resistente" tratando de cambiar sus significados, tal vez porque precisamente estos ya funcionan de manera "alternativa" dentro del contexto nacional occidental -y no oriental- en el que son consumidos, pues forman parte de una cultura de masas "marginal" en la Argentina, como ya se sugirió. Por el contrario, se apropian de los significados que estas ponen en circulación para dar sentidos a su vida cotidiana y construir con sus pares una "(sub)cultura", en tanto el anime es un producto mediático que no responde a los cánones, valores, prácticas y representaciones occidentales tradicionales, y a su vez las prácticas que realizan en torno de este -principalmente el cosplay - resultan "extrañas o anormales" para "el "común” de las personas que no comparten sus consumos.

Aquí cabe subrayar que, a lo largo de este trabajo, se optó por entrecomillar el término "subcultura" o incluso en ocasiones poner entre paréntesis el prefijo $s u b$ - porque los propios jóvenes otakus no utilizan la palabra subcultura para autodefinirse, sino que se perciben como parte de una cultura distinta: así suelen afirmar que "El anime es cultura... a los otakus nos discriminan porque amamos una cultura extranjera" (Álvarez Gandolfi, 2014). Por lo tanto, si se decide nombrarlos como subcultura habría que hacerlo solamente en términos teóricos -complejidad extensible a los usos de categorías que son a la vez prácticas y analíticas, como ocurre con los términos identidad y cultura-, y teniendo en cuenta que "[1]a palabra 'subcultura' rebosa de misterio", como enuncia Hebdige (2004, p. 16). Misterio que, como se ha argumentado aquí, tiende a tratar de resolverse no en un sentido negativo que la asimile a algo "inferior", sino equiparando la noción a la de alternatividad y usándola para indicar una posición de subalternidad o subordinación simbólica. Subalternidad que pareciera querer ser discutida por los propios actores al usar la noción de cultura como categoría de práctica para clasificar a su fandom.

Sin embargo, esto no debe llevarnos a celebrar a las (sub)culturas fan en general, y otaku en particular, como formas simbólicas de resistencia, pues no siempre pueden funcionar como tales. Las subculturas no son autónomas, están insertas en relaciones de poder más amplias. En el caso de los otakus, se advirtió cómo reproducen las jerarquías estructurales de clase, quizás porque la popularización del consumo de anime implica una pérdida de su valor como fuente de alternatividad y diferenciación del resto de la sociedad, en tanto su acceso gradualmente dejaría de ser limitado a unos pocos. Como sostiene Hebdige (2004, pp. 168-169), la distinción entre "originales" y "parásitos" es significativa cuando la subcultura se "publicita", y esto cristaliza una de las contradicciones internas de sus miembros: mantener la privacidad o volverse público. Y al problematizar este tipo de distinciones que se despliegan en el interior del fandom -principalmente mediante un cruce de clivajes generacionales y clasistas- pueden evitarse tanto su autonomización como sus lecturas etnocentristas. Esto a su vez permite una aproximación a sus propias lógicas, las 
cuales no necesariamente se reducen a una "resistencia".

Por otro lado, dicha reproducción interna de jerarquías también podría responder al funcionamiento de la hegemonía, por el cual el poder de las clases dominantes parece -aunque de modo provisional- legítimo y natural. Así, los grupos subordinados adhieren a ciertas concepciones cercanas a los dominantes: entre los otakus de sectores medios, por ejemplo, si bien subordinados en los sentidos que se desarrollaron a lo largo de este trabajo-, suele asociarse el "color de piel negro" a la "pobreza", la "violencia", la "delincuencia", la "suciedad", el "analfabetismo" y consumos musicales como la "cumbia villera", como se anticipó.

Es por ello que no podemos transformar al fan del anime "blanco" y de clase media en un sujeto completamente resistente, ignorando las exclusiones que efectúa. Las divisiones clasistas, en efecto, continúan ejerciendo una gran influencia en las posibilidades que puedan tenerse en todas las esferas de la vida, pues son transmitidas generacionalmente y parecieran estar fuertemente sedimentadas en la organización del orden social.

Finalmente, resultaría pertinente desarrollar análisis posteriores que, a partir de las reflexiones presentadas en este trabajo, problematicen los modos en que se autoperciben los jóvenes otakus pertenecientes a los sectores populares, las maneras en las cuales se identifican con el anime, y cómo entrarían a jugar dentro de esta (sub)cultura. Dichos estudios, a su vez, deberían contemplar la articulación que se da o no en ellos entre el fanatismo por aquellos productos mediáticos japoneses y el fanatismo por la cumbia, entre otras diferenciaciones y objetos de consumo popular -en el sentido de subordinado en un nivel de clase-, pues estos fans suelen ser marginalizados por sus pares de clase media en función de dicho consumo musical, entre otras razones antes enunciadas y a ser indagadas en mayor profundidad. En definitiva, frente al privilegio de la uniformidad ficticia de los grupos de fans del anime que, hasta el momento, predomina en los estudios sobre el fandom otaku, se hace necesario insistir en que se lo tome como una etapa analítica más, a ser complejizada mediante la teorización sobre las desigualdades y los conflictos que involucra como parte de un orden sociosimbólico más amplio. Y la consideración del clivaje de clase como uno de los organizadores significativos de la vida social (Fonseca, 2005) puede contribuir a reintroducir en el análisis tales dimensiones.

\section{Notas}

1 Si bien debido a cuestiones de extensión no es posible detallar aquí el proceso de elaboración de tales datos para reponer el punto de vista de los nativos y los modos en que producen significados identitarios, pueden consultarse otros trabajos en los que se lo desarrolla con mayor profundidad (Álvarez Gandolfi, 2014; 2015; 2016).

$\underline{2}$ Esta última categorización hace referencia a la práctica del cosplay que, en el caso del otakismo o fanatismo por los objetos de la cultura de masas japonesas (Álvarez Gandolfi, 2016), implica una caracterización realista basada en los personajes ficcionales de dichos productos mediante la confección y el uso de vestimentas y accesorios en ciertos contextos específicos de socialización. 
$\underline{3}$ Aquí cabe aclarar que, si bien podría pensarse que en la actualidad habría una valoración positiva del "ser joven", en dicha valoración no entrarían necesariamente todos los distintos modos de serlo: por ejemplo, joven fan del anime. Además, es destacable que la mayoría de los otakus tienen entre 15 y 35 años, y se perciben a sí mismos como "jóvenes", además de que no se sienten comprendidos por los adultos, a cuyo punto de vista suelen asociar con las representaciones mediáticas peyorativas sobre su fanatismo.

4 Para distintas discusiones analíticas respecto del delito -como robo- en su relación con subculturas juveniles y la cultura hegemónica, véanse los trabajos de Daniel Míguez (2008) y David Matza (2014).

$\underline{5}$ Los fanfics son relatos escritos de modo amateur que extrapolan personajes y situaciones de las series animadas japonesas para insertarlos en nuevas tramas; el fan art es una denominación que incluye a las obras plásticas de arte gráfico, principalmente dibujos, realizadas a partir del anime; y el AMV es una obra audiovisual consistente en una yuxtaposición de imágenes y música, cuya edición también toma como base al anime.

$\underline{6}$ Por ejemplo, la mayoría de los hombres destacan a los personajes femeninos "tiernos" y a la vez "distantes" cuyas curvas tienden a ser sobremarcadas y cuya conquista suele representar un "reto", mientras que la mayoría de las mujeres valoran las referencias constantes a relaciones amorosas entre personajes del mismo sexo.

1 No obstante, Hebdige se encarga de aclarar que, aunque proporcionen gran riqueza de detalles descriptivos, los informes basados en la observación participante subestiman el significado de las relaciones de clase y de poder, razón por la cual se decide por encarar una lectura de la superficie textual de las subculturas -su estilo-, en la cual sugiere que dichas relaciones se manifiestan.

$\underline{8}$ En efecto, los jóvenes fans del anime se sienten discriminados por aquellos con quienes conviven en otros ámbitos sociales, como por ejemplo sus compañeros de escuela o trabajo, entre los cuales también reivindican su estilo. De aquí que sea necesario el contraste empírico con las propias experiencias que los miembros de una subcultura tienen de su vida cotidiana, más allá de los espacios de ocio.

$\underline{9}$ Es preciso tener en cuenta que, en la actualidad, podría entenderse que la "comunidad de clase obrera" de posguerra a la que refiere Hebdige ha sufrido mutaciones: por ejemplo, podríamos pensar que en su configuración ha crecido el número de empleados de comercio, servicios y transporte por sobre el número de obreros industriales.

\section{Bibliografía}

Alabarces, P., Salerno, D., Silba, M. y Spataro, C. (2008). Música popular y resistencia: los significados del rock y la cumbia. En Resistencias y mediaciones [pp. 31-58]. Buenos Aires: Paidós. Álvarez Gandolfi, F. (2014). Subcultura otaku. Representaciones, prácticas e identidades juveniles de los fans del manga y el anime en Argentina (Tesis de licenciatura en Ciencias de la Comunicación). Universidad de Buenos Aires, CABA, Argentina. 
Álvarez Gandolfi, F. (2015). Culturas fan y cultura masiva. Prácticas e identidades juveniles de otakus y gamers. La Trama de la Comunicación, 19, 45-65. Disponible en: http://www.latrama.fcpolit.unr.edu.ar/index.php/trama/article/view/514/396.

Álvarez Gandolfi, F. (2016). La cultura otaku y el consumo fan de manga-animé en Argentina: entre el posmodernismo y la convergencia. Vozes \& Diálogo, 15(1), 24-36. Disponible en: https://siaiap32.univali.br/seer/index.php/vd/article/view/8837/5139.

Balderrama Gastelú, L. y Pérez Hernáiz, C. C. (2009). La elaboración del ser otaku desde sus prácticas culturales, la interacción con el otro y su entorno (Tesis de licenciatura en Sociología). Universidad Católica Andrés Bello, Caracas, Venezuela.

Becker, H. (2012). Outsiders: hacia una sociología de la desviación. Buenos Aires: Siglo Veintiuno Editores.

Borda, L. (2012). Bettymaníacos, luzmarianas y mompirris: el fanatismo en los foros de telenovelas latinoamericanas (Tesis de doctorado en Ciencias Sociales). Universidad de Buenos Aires, CABA, Argentina.

Borda, L. y Álvarez Gandolfi, F. (2014). El silencio de los otakus. Estereotipos mediáticos y contraestrategias de representación. Papeles de Trabajo, 8(14), 50-76. Disponible en: http://www.idaes.edu.ar/papelesdetrabajo/paginas/Documentos/n14/1.4.\%20Borda\%20y \%20Gandolfi $\% 20 \mathrm{El} \% 20$ silencio $\% 20 \mathrm{de} \% 201 \mathrm{os} \% 20$ otakus.pdf

Bourdieu, P. (1988). Los usos del pueblo. En Cosas dichas [pp. 152-157]. Buenos Aires: Gedisa.

Brubaker, R. y Cooper, F. (2001). Más allá de "identidad". Apuntes de Investigación del CECYP, Año 5, 7, 30-67.

Chaves, M. (2010). Jóvenes, territorios y complicidades. Buenos Aires: Espacio Editorial.

Cobos, T. L. (2010). Animación japonesa y globalización. La latinización y la subcultura otaku en América Latina. Razón y Palabra, 72, 1-28.

Del Vigo, G. A., y Carpenzano, N. A. (2014). Más allá del mundo feliz del fin de semana. Cosplay en la Argentina (Tesis de licenciatura en Ciencias de la Comunicación, Facultad de Ciencias Sociales). Universidad de Buenos Aires, CABA, Argentina.

Eagleton, T. (1998). Prefacio. En Las ilusiones del posmodernismo [pp. 11-15]. Barcelona: Paidós.

Fonseca, C. (2005). La clase social y su recusación etnográfica. Etnografías Contemporáneas, 1, 117-138.

Furbank, P. N. (2005). La clase y los sociólogos. En Un placer inconfesable o la idea de clase social [pp. 113-127]. Buenos Aires: Paidós.

García Núñez, R., y García Huerta, D. (2014). Una aproximación a los estudios sobre los otakus en Latinoamérica. Contextualizaciones Latinoamericanas, 10, 1-9.

Garriga Zucal, J. (s/f). Reseña de Subcultura, de Dick Hebdige. Disponible en: http://envios.unsam.edu.ar/escuelas/humanidades/centros/c cie/pdf/n2/Resenas $2 . p d f$ 
Grimson, A. (2010). Culture and Identity: two different notions. Social Identities, 16(1), 63-79.

Grimson, A. y Semán, P. (2005). Presentación: la cuestión “cultura”. Etnografias Contemporáneas, $1,1-12$.

Hall, S. (1981). La cultura, los medios de comunicación y el "efecto ideológico". En J. Curran et al. (Comps.), Sociedad y comunicación de masas [pp. 357-392]. México: FCE.

Hall, S., y Jefferson, T. (Eds.) (2010). Resistencia a través de rituales. Subculturas juveniles en la Gran Bretaña de la Posguerra. La Plata: UNLP.

Hall, S. (2011). Introducción: ¿quién necesita “identidad”? En S. Hall y P. Du Gay (Comps.), Cuestiones de identidad cultural [pp. 13-39]. Buenos Aires: Amorrortu.

Hebdige, D. (2004). Subcultura. El significado del estilo. Barcelona: Paidós.

Ito, M., Okabe, D. y Tsuji, I. (Eds.) (2012). Fandom Unbound: Otaku Culture in a Connected World. New Haven: Yale University Press.

Kellner, D. (2011). Introducción. En Cultura mediática. Madrid: Akal.

Lenarduzzi, V. (2005). El orden del sentir: una mediación entre la ideología y el sentido común. Constelaciones, 2, 1-12.

Matza, D. (2014). Delincuencia y deriva. Buenos Aires: Siglo Veintiuno Editores.

Míguez, D. (2008). Delito y cultura. Buenos Aires: Biblos.

Perillán, L. (2009). Otakus en Chile (Tesis de licenciatura en Antropología). UCh, Santiago, Chile.

Reguillo Cruz, R. (2012). Culturas juveniles. Formas políticas del desencanto. Buenos Aires: Siglo Veintiuno Editores.

Saintout, F. (2006). Jóvenes: el futuro llegó hace rato. Comunicación y estudios culturales latinoamericanos. La Plata: UNLP.

Saintout, F. (2013). Los jóvenes en la Argentina. Buenos Aires: UNQui.

Thompson, E. P. (1980). La formación de la clase obrera en Inglaterra. Madrid: Capitán Swing.

Williams, R. (1981). Hacia una sociología de la cultura. En Sociología de la cultura [pp. 9-30]. Barcelona: Paidós. 